\title{
Diagnóstico molecular do granuloma lepróide canino, a partir de cortes histológicos emblocados em parafina, pela técnica de reação em cadeia de polimerase (PCR) - estudo retrospectivo (2002-2009)
}

\section{Molecular diagnosis of Canine Leproid Granuloma out of paraffin- embedded histological cuts using polymerase chain reaction (PCR) - a retrospective study (2002-2009)}

\author{
Simoni Maruyama ${ }^{*} ;$ Paulo Eduardo Brandão²; \\ Alessandra Marnie Martins Gomes de Castro ${ }^{3}$; Nilceo Schwery Michalany ${ }^{4}$; \\ Janet Fyfe ${ }^{5}$; Richard Malik ${ }^{6}$; Carlos Eduardo Larsson ${ }^{7}$
}

\section{Resumo}

O Granuloma lepróide canino (GLC) ou "lepra canina" consiste em micobacteriose, com quadro dermatopático que conta com aspectos ainda obscuros, principalmente quanto ao seu modo de transmissão e agente etiológico envolvido. Com a finalidade de se verificar a caracterização gênica da micobactéria em questão, procedeu-se estudo a partir de cortes histológicos, de animais com diagnóstico estabelecido da enfermidade. A amostragem foi composta de 13 cães, atendidos no Serviço de Dermatologia do HOVET/USP. Tal material foi posteriormente submetido às técnicas de reação em cadeia de polimerase (PCR), "nested" e em tempo real. O método da PCR "nested" confirmou a presença do agente em apenas $18,7 \%$ dos animais. Enquanto que, em $69,2 \%$ das amostras, o DNA da micobactéria envolvida foi detectado pela PCR em tempo real, demonstrando ser neste estudo, o método de maior sensibilidade. Pôde-se concluir ainda que a espécie de micobactéria causadora do Granuloma lepróide canino nos cães brasileiros possui homologia gênica de $100 \%$, quando comparada às amostras provindas de animais de estudos estrangeiros.

Palavras-chave: Granuloma lepróide, cães, PCR

\begin{abstract}
Canine leproid granuloma or "canine leprosy" is a mycobacteriosis that has a dermatopathic framework, which includes aspects that are still unclear, especially regarding its mode of transmission and etiological agent. In order to verify the genetic characterization of the mycobacteria that is involved in the condition, the present study analyzed histological cuts from animals with an established diagnosis of such disorder.
\end{abstract}

1 Discente do Programa de Pós-Graduação em Clínica Veterinária, Dept ${ }^{\circ}$ de Clínica Médica, Faculdade de Medicina Veterinária e Zootecnia, Universidade de São Paulo, FMVZ/USP, São Paulo, SP. E-mail: simonivet@gmail.com

2 Prof. Dr., Dept ${ }^{\circ}$ de Medicina Veterinária Preventiva e Saúde Animal, FMVZ/USP, São Paulo, SP. E-mail: paulo7926@usp.br

3 Prof ${ }^{a}$. Dra , Curso de Medicina Veterinária, Complexo Educacional Faculdades Metropolitana Unidas, FMU, Veterinária, São Paulo, SP, Brasil. E-mail: alessandramarnie@gmail.com

4 Prof. M.e, Laboratório Paulista de Dermatopatologia, São Paulo, SP. E-mail: labpaulista@uol.com.br

5 Prof. Dr., Ms, PhD, Victorian Infectious Diseases Reference Laboratory, North Melbourne, Victoria, Austrália. E-mail: janet. fyfe@mh.org.au

6 Prof. Dr., Ms, PhD, Centre For Veterinary Education, Conference Centre B22, The University of Sydney, Sydney, SW, Austrália. E-mail: r.malik@vetc.usyd.edu.au

7 Prof. Dr. Titular, Dept ${ }^{\circ}$ de Clínica Médica da Faculdade de Medicina Veterinária e Zootecnia, FMVZ/USP, São Paulo, SP. E-mail: larsderm@usp.br

* Autor para correspondência 
The study samples were taken from of 13 dogs that were assisted at the HOVET / USP Dermatology Service. This material was subsequently subjected to "nested" and real-time polymerase chain reaction (PCR). The nested PCR confirmed the presence of the agent in $18.7 \%$ of the animals, whereas the realtime PCR detected $69.2 \%$ of samples with DNA of the mycobacterium, thus proving that such method presents higher sensitivity. Furthermore, it was observed that the species of mycobacterium that causes Canine Leproid Granulnoma in dogs from Brazil presents a 100\% genetic homology when compared to samples obtained from animals in studies abroad.

Key words: Leproid Granuloma, dogs, PCR

\section{Introdução}

O Granuloma lepróide canino (GLC) se constitui em enfermidade tegumentar que acomete cães, causada por bacilos álcool-ácido-resistententes, Gram positivos, aeróbios estritos, não formadores de esporos, imóveis, não capsulados, pertencentes à família Mycobacteriaceae, ordem Actinomycetales, gênero Mycobacterium (GREENE, 2006; MALIK et al., 2006) ou, ainda, segundo Fyfe et al. (2008) de espécie relacionada ao Mycobacterium simiae ou Mycobacterium sp. CLGS ("canine leproid granuloma syndrome”). Outras designações para o agente etiológico, também, estão dispostas na bibliografia, tais como Mycobacterium sp. cepa CLGS ou "nova" espécie de micobactéria que causa o Granuloma lepróide canino (MALIK et al., 2006) e, finalmente, Mycobaterium murphy, segundo Acha (2009), uma vez que Hughes et al. (2000) e Foley et al. (2002) concluíram que o fragmento seqüenciado e disposto no banco de dados do Genbank é intitulado "Mycobacterium sp. Murphy 16S ribosomal RNA".

Como característica toda especial da(s) micobactéria(s) envolvida(s), ressalta-se a impossibilidade de seu cultivo nos meios clássicos e especiais ora empregados (LEMARIE, 1999; GREENE, 2006; MALIK et al., 2006; SMITS et al., 2012). Tal aspecto insólito é, também, compartilhado pelo agente etiológico da lepra felina ("Micobactéria relacionada ao Mycobacterium simiae”), que ocasiona granulomas na pele e panículo em gatos, à semelhança do agente do Granuloma lepróide canino (FYFE et al., 2008; MALIK et al., 2013).

Historicamente, tais bactérias têm sido subdivididas em diversos grupos e espécies individualizadas, de acordo com particularidades bioquímicas e fatos relacionados ao seu cultivo. Portanto, com o advento das técnicas de biologia molecular, os estudos referentes ao seqüenciamento genético têm ampliado e propiciado maior precisão à classificação taxonômica. Hoje, pode-se dizer que diagnósticos estabelecidos pela biologia molecular, segundo as características genéticas da micobactéria em tela, tem demonstrado mais viabilidade relativamente ao diagnóstico embasado em suas propriedades fenotípicas (GREENE, 2006). Ou seja, a classificação de acordo com a formação de pigmento e o tempo necessário ao crescimento em cultivo- lento e rápido - embora didática, mas já não é mais considerada como precisa na distinção das espécies. A atual identificação é executada mediante análise bioquímica dos ácidos micólicos da parede da bactéria e pelas técnicas de biologia molecular (AZULAY, 2008; OLIVEIRA, 2009).

O diagnóstico do Granuloma lepróide canino, de forma usual e corriqueira, na clínica de pequenos animais, é estabelecido tanto pelo exame citobacterioscópio das lesões cutâneas (MALIK et al., 2013) bem como pelo exame histopatológico de fragmentos obtidos por biópsia (MALIK et al., 2006). Mas com o advento de técnicas moleculares mais acessíveis, tem permitido, principalmente, em laboratórios especializados, o uso da reação em cadeia de polimerase (PCR) em vários âmbitos na medicina veterinária.

Em medicina humana, tal metodologia permite a investigação diagnóstica de distintas amostras biológicas, mesmo quando o DNA está presente em diminutas quantidades. Resquícios de saliva, esfregaço de mucosa oral, sangue, bulbos capilares, tecidos emblocados em parafina, fragmentos 
ósseos, gotas de sêmen, dentre outros, propiciam informações importantes pois, rotineiramente, amostras de tecidos são removidas do corpo humano para análise, com vistas ao diagnóstico de doenças e os fragmentos oriundo desses materiais, fixados em formol, incluídos em parafina podem ser mantidos em laboratórios, uma vez que tais espécimens representam importante material biológico para investigação médico legal para fins de pesquisa acadêmica. Assim sendo, o aperfeiçoamento dos métodos de extração de DNA, a partir de tecido parafinado, de forma a torná-los de execução simples e de menor custo, facilita enormemente a utilização desses materiais em estudos retrospectivos, trazendo grande contribuição para a investigação da etiologia e da epidemiologia das enfermidades (JACKSON et al., 1990; SIMONATO et al., 2007).

\section{Objetivos}

O presente estudo objetivou a confirmação do diagnóstico do Granuloma lepróide canino, a partir de amostras de tecido cutâneo, fixados em formol e emblocados em parafina, pela técnica da reação em cadeia de polimerase (PCR), afora verificar se a sequência gênica da micobactéria encontrada nas lesões de cães brasileiros corresponderia àquela dos casos dispostos em estudos estrangeiros.

\section{Material e Métodos}

Foram utilizados cortes histológicos, provenientes de treze animais da espécie canina, atendidos, no decorrer dos anos de 2002 a 2009, junto ao Serviço de Dermatologia (SD) do Departamento de Clínica Médica (VCM) e do Hospital Veterinário (HOVET) da Faculdade de Medicina e Veterinária e Zootecnia da Universidade de São Paulo (FMVZ/ USP), com diagnóstico clínico estabelecido de Granuloma lepróide canino, confirmado pelo exame histopatológico cutâneo.

Os cortes histológicos, fixados em formol a 10\% e emblocados em parafina, foram obtidos junto ao acervo do Laboratório Paulista de Dermatopatologia, para onde são encaminhadas as amostras de todos os animais submetidos à biópsia no Serviço de Dermatologia do HOVET da FMVZ/USP.

\section{Amostras}

Obtidos os blocos parafinados, contendo as amostras biopsiadas e diagnosticadas histologicamente, estes foram seccionados, utilizando-se de micrótomo, previamente higienizado, dispondo de lâminas descartáveis utilizadas para cada um dos blocos. Os cortes, com espessura de 10 a $20 \mu \mathrm{m}$, foram acondicionados, individualmente, em tubos plásticos, identificados, vedados, com capacidade de 1,5 mL.

Posteriormente, em acordo e em anuência a todos os requisitos legais, sanitários e alfandegários de exportação, de material biológico para pesquisa, as amostras foram enviadas ao Victorian Infectious Diseases Reference Laboratory ${ }^{1}$, para a realização das técnicas de diagnóstico molecular.

\section{Processamento das amostras}

As amostras que foram processadas segundo a metodologia proposta por Fyfe et al. (2008) para o protocolo de PCR “nested” e por Fyfe et al. (2007) para o protocolo de PCR em tempo real, seguem descritas abaixo:

\section{Extração do DNA}

Iniciou-se com a retirada da parafina e com a adição de histolene (Fronine Pty.Ltd.) aos tubos, contendo as amostras, seguida da adição de $1 \mathrm{~mL}$ de etanol absoluto e submissão à centrifugação a 13.000 rpm, por 5 minutos, em microcentríguga (Heracus). O DNA foi extraído, do "pellet" de tecido, usando o minikit QIAamp DNA (Qiagen Inc., Valencia, CA) seguido do protocolo de recuperação do DNA, precedido por incubação de 24 horas, a $56^{\circ} \mathrm{C}$, em solução tampão (50mM de Tris-HCl, pH 7,5, 10mM 
de EDTA, 0,5\% [p/vol] de dodecil sulfato de sódio, $50 \mathrm{mM}$ de $\mathrm{Na} \mathrm{Cl}, 300 \mu \mathrm{g} / \mathrm{mL}$ de proteinase $\mathrm{K}$ )

\section{PCR "nested"}

$\mathrm{O}$ procedimento foi executado, segundo o descrito por Fyfe at al. (2008): os "primers" utilizados, para a amplificação por PCR das regiões variáveis do genoma, neste estudo foram os seguintes: Ec 16S.1390p (TTG TAC ACA CCG CCC GTC A), Mb23S.44n (TCT CGA TGC CAA GGC ATC CAC C) para a primeira reação para o gene ITS1, respectivamente, senso e anti-senso. Já os "primers" para a segunda reação do gene ITS1 foram: SP1 (ACC TCC TTT CTA AGG AGC ACC) e SP2 (GAT GCT CGC AAC CAC TAT CCA), respectivamente, senso e anti-senso.

A amplificação da região ITS1 foi concretizada usando um protocolo de PCR "nested", onde se aplicam: $0,5 \mu \mathrm{L}$ de DNA extraído a $20 \mu \mathrm{L}$ da mistura de PCR com o volume final de $25 \mu \mathrm{L}$ do tampão de PCR com 1,5 mM Mg Cl 2 (Qiagen Inc., Valencia, CA), $200 \mu \mathrm{M}$ de trifosfato deoxinucleosídeos (dNTPs), "primers" Ec 16S.1390p e Mb23S.44n ( $2 \mu \mathrm{M}$ de cada), e 1,25 U de Taq DNA polimerase (Qiagen). Tal amplificação foi realizada no termociclador (Mastercycler gradient, Eppendorf) com uma etapa inicial de desnaturação do DNA a $95^{\circ} \mathrm{C}$ por 5 minutos, seguida de 38 ciclos de $94^{\circ} \mathrm{C}$ por 1 minuto para a desnaturação, $62^{\circ} \mathrm{C}$ por 1 minuto para o anelamento dos oligonucleotídeos iniciadores, $72^{\circ} \mathrm{C}$ por 1 minuto para a extensão das fitas e um ciclo final de $72^{\circ} \mathrm{C}$ por 5 minutos para extensão final.

Para a segunda amplificação (PCR “nested”) utilizou-se de $2,5 \mu \mathrm{L}$ dos produtos da primeira PCR, em volume final de $50 \mu \mathrm{L}$, contendo tampão de PCR com 1,5 mM de $\mathrm{MgCl}_{2}$ (Qiagen), 200 $\mu \mathrm{M}$ de dNTPs, primers SP1 e SP2 $(2 \mu \mathrm{M}$ de cada $)$ e 2,5 U de Taq DNA polimerase (Qiagen). Esta amplificação foi realizada no mesmo termociclador com uma etapa inicial de desnaturação do DNA a $94^{\circ} \mathrm{C}$ por 2 minutos, seguida de 35 ciclos de $94^{\circ} \mathrm{C}$ por 15 segundos, $59^{\circ} \mathrm{C}$ por 30 segundos e $72^{\circ} \mathrm{C}$ por 30 segundos, e um ciclo final de $72^{\circ} \mathrm{C}$ por 5 minutos para extensão final.

O método incluiu um processo de extração com controle negativo, um controle negativo para a PCR, um controle positivo contendo $100 \mathrm{fg}$ de DNA, extraído de Mycobacterium tuberculosis H37Rv, e, finalmente, controles para inibição, contendo DNA extraído (100 fg) de M. tuberculosis.

\section{Análise dos produtos da PCR}

Os produtos da PCR foram submetidos à eletroforese em gel de agarose a $2 \%$ e os tamanhos dos fragmentos foram estimados em comparação com um DNA ladder Gene Ruler 1 - Kb (MBI Fermentas, Amherst, NY) ou pUC19/Mspl marker 23 (MBI Fermentas). Os fragmentos foram purificados a partir dos cortes de gel de agarose, usando o kit High Pure PCR product purification (Roche), de acordo com as instruções do fabricante.

\section{Análise da sequência de DNA}

Aanálise das sequências dos produtos purificados da PCR"nested", 224bp, num total de 5 amostras, foram realizadas usando o kit de seqüenciamento BigDye Terminator v3.1 cycle (Applied Biosystems, Foster City, CA), segundo as instruções do fabricante. Os "primers" empregados foram os mesmos que aqueles descritos na amplificação pela PCR. As reações foram analisadas no $3730 \mathrm{~S}$ Genetic analyzer (Applied Biosystems), os dados seqüenciais foram editados usando Bionumerics v4.0 (Applied Maths, Gent, Belgium) e as buscas nas bases de dados do GenBank foram feitas usando o algoritmo BLASTN.

\section{Análise filogenética}

As cinco sequências foram alinhadas e comparadas (1000 replicações de bootstraps) com as sequências disponíveis no Genbank 
da região ITS1 usando ClustalX e a análise de máxima verossimilhança foi feita usando BioEdit (THOMPSON et al., 1997; HALL, 1999).

Número de acesso da sequência de nucleotídeos

A sequência determinada para Mycobacterium sp. cepa CLGS, região parcial ITS1 (183 nt) está depositada no Genbank; cujo número de acesso é EF611177.

\section{PCR em tempo real}

O protocolo desta técnica foi realizado com base no trabalho descrito por Fyfe et al. (2007), com algumas poucas variações, já que os "primers" utilizados, no presente estudo, foram desenhados e direcionados especificamente para a região ITS1 do gene do Mycobacterium relacionado ao Granuloma lepróide canino (CLGS) : CAC TAT TGG GCC CTG AGA (senso) e AAG ACG GAG GGA CAC CAC TTC (anti-senso). Outra modificação foi aquela relativa ao uso do marcador fluorogênico, já que se optou pelo SYBRGreen e não pela sonda
Taqman. As reações de $25 \mu \mathrm{L}$ como volume final foram compostas, em cada uma, por: $12,5 \mu \mathrm{L}$ de SYBRGreen PCR Mastermix (Applied Biosystems), $1 \mu \mathrm{L}$ do primer senso (com 200nM na concentração final), $1 \mu \mathrm{L}$ do primer anti-senso (com 200nM na concentração final), 9,5 $\mu \mathrm{L}$ de água deionizada e $1 \mu \mathrm{L}$ de DNA extraído.

\section{Resultados}

Em nove (69,2\%) das 13 amostras de pele, com diagnóstico histopatológico e clínico previamente estabelecido de Granuloma lepróide canino, detectou-se DNA de Mycobacterium sp cepa CLGS pela PCR em tempo real . No entanto, quando da realização da PCR “nested”, em apenas três $(18,7 \%)$ dos animais se confirmou a presença do DNA do agente etiológico da enfermidade (Tabela 1).

Quanto à análise filogenética, verificou-se identidade dos produtos obtidos, uma vez que o sequenciamento do DNA foi confirmado com a equivalência de $100 \%$ com a sequência disposta no acesso EF611177 do Genbank.

Tabela 1. Caracterização dos cães com Granuloma lepróide canino, segundo a identificação, definição racial, sexo e idade submetidos aos protocolos de PCR “nested”, PCR em tempo real e presença de DNA relativa ao GLC. Serviço de Dermatologia do HOVET - FMVZ/USP -2002 a 2009. São Paulo (2013).

\begin{tabular}{ccccccc}
\hline $\begin{array}{c}\text { Animal/ } \\
\text { prontuário }\end{array}$ & Raça & Sexo & $\begin{array}{c}\text { Idade } \\
\text { (anos) }\end{array}$ & $\begin{array}{c}\text { PCR } \\
\text { "nested" }\end{array}$ & $\begin{array}{c}\text { PCR } \\
\text { em tempo real }\end{array}$ & DNA GLC \\
\hline 123344 & Golden Retriever & $\mathrm{F}$ & 3 & $\mathrm{~N}$ & $\mathrm{~N}$ & não \\
90417 & Labrador & $\mathrm{M}$ & 4 & $\mathrm{~N}$ & $\mathrm{D}$ & sim \\
136959 & Boxer & $\mathrm{M}$ & 2 & $\mathrm{D}$ & $\mathrm{D}$ & sim \\
143919 & Labrador & $\mathrm{F}$ & 4 & $\mathrm{~N}$ & $\mathrm{~N}$ & não \\
156754 & Cocker Spaniel & $\mathrm{M}$ & 4 & $\mathrm{~N}$ & $\mathrm{D}$ & sim \\
157828 & SRD & $\mathrm{F}$ & 9 & $\mathrm{~N}$ & $\mathrm{D}$ & sim \\
162712 & Boxer & $\mathrm{F}$ & 4 & $\mathrm{D}$ & $\mathrm{D}$ & sim \\
175041 & Boxer & $\mathrm{M}$ & 8 & $\mathrm{~N}$ & $\mathrm{D}$ & sim \\
140913 & Boxer & $\mathrm{M}$ & 8 & $\mathrm{~N}$ & $\mathrm{D}$ & sim \\
171272 & Boxer & $\mathrm{M}$ & 6 & $\mathrm{~N}$ & $\mathrm{D}$ & sim \\
194037 & Boxer & $\mathrm{F}$ & 3 & $\mathrm{~N}$ & $\mathrm{~N}$ & não \\
182591 & Pitbull & $\mathrm{M}$ & 5 & $\mathrm{~N}$ & $\mathrm{~N}$ & não \\
188318 & Boxer & $\mathrm{M}$ & 5 & $\mathrm{D}$ & $\mathrm{D}$ & sim \\
\hline
\end{tabular}

$\mathrm{SRD}=$ sem raça definida; $\mathrm{F}=$ fềmea; $\mathrm{M}=$ macho; $\mathrm{N}=\mathrm{DNA}$ não detectado; $\mathrm{D}=\mathrm{DNA}$ detectado.

Fonte: Elaboração dos autores. 


\section{Discussão}

Em relação às amostras negativas na PCR "nested", observou-se que estas apresentaram o mesmo resultado na PCR em tempo real, ou seja a capacidade de detecção neste último método foi superior e, portanto, o número de falso-negativos, menor.

Foi evidenciado, ainda, que em várias amostras, pressupostamente negativas, provavelmente houve a degradação do DNA, de maneira que impossibilitasse a sua detecção. Dentre as causas possíveis envolvidas, a título de exemplo, enumeram-se: o tempo de fixação da peça em formol e as técnicas empregadas para retirada da parafina que se utiliza de solventes, por vezes, orgânicos. A possibilidade do DNA ter-se-à desintegrado, talvez devido à fixação em formol, foi aventada em trabalho de Acha (2009) que se deparou, também, com algumas amostras negativas na PCR. Devese considerar, ainda, que, no caso destas amostras negativas pela PCR convencional e por aquela em tempo real, outras etiologias podem ser atribuídas às lesões que não micobacterianas, a exemplo de outros quadros tegumentares infecciosos, neoplásicos e degenerativos.

A fixação de tecidos com formol a 10\% trata-se de método prático e eficiente para sua preservação sendo, portanto, amplamente utilizado em anatomia patológica. Contudo esse tipo de fixação resulta, habitualmente, no enovelamento de proteínas nucleares, na formação de ligações entre proteínas e DNA e, ainda, na fragmentação do mesmo, o que dificulta, sobremaneira, a extração dessa classe de moléculas de tecidos previamente fixados. Além disso, vários outros passos podem influenciar a obtenção de amplificações positivas, a começar pela forma de obtenção dos cortes e a desparafinização que, além de ser opcional, pode ser realizada através de calor ou lavagens com solventes, tal como o xilol; o tempo de digestão em proteinase $\mathrm{K}$ e a concentração desta última no tampão de digestão (SIMONATO et al., 2007). Hughes et al.
(2000) e Malik et al. (2013) verificaram diferenças entre os resultados da PCR de DNA, extraído de amostras de tecido "a fresco" e de material oriundo de tecidos emblocados em parafina. Possivelmente, houve, segundo os autores, a degradação de DNA devido à presença residual de formalina, levando a uma quantidade menor de material genético, se comparado com o tecido não fixado.

Dentre os exames de alta sensibilidade e especificidade, a reação em cadeia da polimerase (PCR), método este da biologia molecular, destacase pela possibilidade de amplificar ou multiplicar fragmentos ou vestígios de DNA de células, incluídas as bacterianas, permitindo, assim, sua fácil detecção. Esse método vem sendo hoje aplicado, frequentemente, em pesquisas de doenças infecciosas de variada etiologia (SANTOS et al., 2007). Em relação à investigação de dermatoses tropicais, em medicina humana, muito se tem adquirido com a utilização da biologia molecular, sendo que o objetivo mais atual se volta para o auxílio no desenvolvimento de fármacos e de vacinas para o seu controle, em especial no caso da hanseníase (ROSELINO, 2008).

A importância na realização da PCR reside, justamente, no fato de ser uma técnica bastante sensível e específica, principalmente, para a identificação de patógenos presentes em lesões às vezes tidas, como "estéreis", tal como no piogranuloma estéril, onde se deve considerar o diagnóstico diferencial tanto para leishmaniose como para micobacteriose (ROURA; SANCHEZ; FERRER, 1999; CORNEGLIANI et al., 2005).

$\mathrm{Na}$ Irlanda, Hughes et al. (2000) concluíram que a partir do produto da PCR (16S do RNA ribossômico) de material oriundo de 12 cães, a micobactéria presente demonstrou similaridade gênica com $M$. tilburgii, $M$. simiae e M.genavense, além da homologia de 99 a 100\% com aquela de cães australianos e neozelandeses (MALIK et al., 1998). Já, Foley et al. (2002) constataram que cães criados no vale central da Califórnia, também, 
compartilhavam os mesmos aspectos clínicos e genéticos relativos ao Granuloma lepróide canino, comparativamente àqueles da Austrália e Nova Zelândia.

Recentemente, no Brasil, Acha (2009) conduziu, em trabalho de pós-graduação, estudo acerca do Granuloma lepróide canino, com cães oriundos dos estados de Minas Gerais e São Paulo. A partir da realização da PCR e do seqüenciamento gênico parcial da região $16 \mathrm{~S}$ do RNA ribossômico, identificou-se o Mycobacterium murphy, também descrito por Hughes et al. (2000) e Foley et al. (2002), como um dos principais agentes envolvidos na etiologia da enfermidade.

No presente trabalho, evidenciou-se que houve similaridade entre as amostras oriundas de cães brasileiros atendidos no HOVET da FMVZ/USP e aqueles oriundos da Austrália, de sequência gênica determinada para Mycobacterium sp. cepa CLGS, região parcial ITS1 (número de acesso no Genbank EF611177). Porém, as pesquisas para tal região gênica ainda são escassas, o que indica a necessidade de estudos futuros para um maior detalhamento dos resultados obtidos.

Da casuística brasileira permanecem, ainda, várias lacunas a ser esclarecidas e, uma delas seria a indagação se os resultados do material provindo de cães, provenientes das outras regiões do Brasil, coincidiriam com os dados estabelecidos no presente trabalho e naquele de Acha (2009), de Minas Gerais e São Paulo, uma vez que ambos estão somente restritos à região sudeste brasileira. Sabe-se que, em análises preliminares de outras localidades a exemplo do Paraná (FARIAS et al., 2008), Rio de Janeiro (CÁRDIA et al., 2009), Distrito Federal (SEIXAS et al., 2008) e Bahia (TORRES et al., 2006), algumas informações relacionadas somente aos aspectos clínicos, epidemiológicos e de resposta à terapia guardam correspondência entre si.

\section{Conclusões}

Em função da metodologia empregada no presente trabalho, pôde-se concluir que a PCR em tempo real permitiu o diagnóstico de confirmação do Granuloma lepróide canino a partir de cortes histológicos emblocados em parafina. Já o método da PCR em tempo real apresentou maior sensibilidade relativamente ao método da PCR "nested". E, a micobactéria causadora do Granuloma lepróide canino nos cães brasileiros, da casuística de atendimento no HOVET da FMVZ/ USP, apresentou homologia de $100 \%$ frente ao Mycobacterium sp. cepa CLGS de amostras isoladas de cães australianos.

\section{Observações}

Trabalho aprovado pela Comissão de Bioética da Faculdade de Medicina Veterinária e Zootecnia da Universidade de São Paulo sob o protocolo número 1277/2007.

\section{Agradecimentos}

À verba PROAP para o material da pesquisa. À Sheila Oliveira de Souza e Karen L. Ferrari.

(LABMAS -VPS/FMVZ-USP) pelo auxílio nos exames de PCR. Ao Victorian Infectious Diseases.

Reference Laboratory pelo processamento das amostras.

\section{Referências}

ACHA, L. M. R. Granuloma lepróide canino: aspectos clínicos, epidemiologia, histopatologia e biologia molecular - estudo retrospectivo de 38 casos. 2009. Dissertação (Mestrado em Medicina Veterinária) - Universidade Federal de Viçosa, MG. Disponível em: <ftp://ftp.bbt.ufv.br/teses/medicina $\% 20$ veterinaria/2009/216709f.pdf>. Acesso em: 20 jan. 2010.

AZULAY, R. D. Dermatologia. 5. ed. Rio de Janeiro: Guanabara Koogan, 2008. 983 p. 
CÁRDIA, A. S.; ANTUNES, P. G.; PLIEGO, C. M.; ALVIM, A. P. V.; MICHALANY, N. S. Micobacteriose no estado do Rio de Janeiro. In: CONGRESSO BRASILEIRO DE MEDICINA VETERINÁRIA, 36., 2009, Porto Seguro. Anais... Porto Seguro: Sociedade Brasileira de Medicina Veterinária, 2009. p. 15.

CORNEGLIANI, L.; FONDEVILA, D.; VERCELLI, A.; MANTERO, G.; FONDATI, A. PCR technique detection of Leishmania spp. but not Mycobacterium spp. in canine cutaneous 'sterile' pyogranuloma/granuloma syndrome. Veterinary Dermatology, Oxford, v. 16, n. 4, p. 233-238, 2005.

FARIAS, M. R.; CASAGRANDE, T. A. C.; WERNER, J.; CAVALCANTE, C. Z. Retrospective study (19982007) of canine leproid granuloma syndrome in Curitiba, Brazil. In: WORLD CONGRESS OF VETERINARY DERMATOlOGY, 6., 2008, Hong Kong. Proceedings... Hong Kong: The Asian Society of Veterinary Dermatology, 2008. p. 64.

FOLEY, J. E.; BORHESSON, D.; GROSS, T. L.; RAND, M.; NEEDHAM, M.; POLAND, A. Clinical, microscopic and molecular aspects of canine leproid granuloma in the United States. Veterinary Pathology, London, v. 39, n. 2, p. 234-239, 2002.

FYFE，J. A.; McCOWAN, C.; O'BRIEN, C. R.; GLOBAN, M.; BIRCH, C.; REVILL, P.; BARRS, V. R. D.; WAYNE, J.; HUGHES, M. S.; HOLLOWAY, S.; MALIK, R. Molecular characterization of a novel fastidious mycobacterium causing lepromatous lesions of the skin, subcutis, cornea, and conjunctiva of cats living in Victoria, Australia. Journal of Clinical Microbiology, Barcelona, v. 46, n. 2, p. 618-626, 2008.

FYFE, J. A. M.; LAVENDER, C. J.; JOHNSON, P. D. R.; GLOBAN, M.; SIEVERS, A.; AZUOLAS, J.; STINEAR, P. T. Development and application of two multiplex realtime PCR assays for the detection of Mycobacterium ulcerans in clinical and environmental samples. Applied and Environmental Microbiology, Washington D.C., v. 73, n. 15, p. 4733-4740, 2007.

GREENE, C. E. Mycobacterial infections. In:

Infectious diseases of the dog and cat. 3. ed. Saint Louis: Saunders Elsevier, 2006. 1387 p.

HALL, T. BioEdit: a user-friendly biological sequence alignment editor and analysis program for Windows 95/98/NT. Nucleic Acids Symposium Series, Oxford, v. 1, n. 41 , p. 95-98, 1999.

HUGHES, M. S.; JAMES, G.; BALL, N.; SCALLY, M.; MALIK, R.; WIGNEY, D. I.; MARTIN, P.; CHEN, S.; MITCHELL, D.; LOVE, D. N. Identification by $16 \mathrm{~S}$ rRNA gene analysis of a potential novel mycoobacterial species as an etiological agent of canine leproid granuloma syndrome. Journal of Clinical Microbiology, Barcelona, v. 38, n. 3, p. 953-959, 2000.

JACKSON, D. P.; LEWIS, F. A.; TAYLOR, G. R.; BOYLSTON, A. W.; QUIRKE, P. Tissue extraction of DNA and RNA and analysis by the polymerase chain reaction. Journal of Clinical Pathology, London, v. 43, n. 6, p. 499-504, 1990.

LEMARIE, S. L. Mycobacterial dermatitis. The Veterinary Clinics of North America: Small Animal Practice, Philadelphia, v. 29, n. 6, p. 1291-1301, 1999.

MALIK, R.; BRONWYN, S.; REPPAS,G.; LAPRIES, C.; O'BRIEN, C.; FYFE, J. Ulcerated and nonulcerated nontuberculous cutaneous mycobacterial granulomas in cats and dogs. Veterinary Dermatology, Oxford, v. 24, n. 1, p. 146-e33, 2013.

MALIK, R.; HUGHES, M. S.; MARTIN, P.; WIGNEY, D. Canine leproid granuloma syndrome (Canine leprosy). In: GREENE, C. E. Infectious diseases of the dog and cat. 3. ed. Saint Louis: Saunders Elsevier, 2006. p. 480482 .

MALIK, R.; LOVE, D. N.; WIGNEY, D. I.; MARTIN, P. Mycobacterial nodular granulomas affecting the subcutis and skin of dogs (canine leproid granuloma syndrome). Australian Veterinary Journal, New South Wales, v. 76, n. 6, p. 403-407, 1998.

OLIVEIRA, M. L. W. Infecções por micobactérias. In: RAMOS-E-SILVA, M. R.; CASTRO, M. C. R. Fundamentos de dermatologia. Rio de Janeiro: Atheneu, 2009. p. 907-936.

ROSELINO, A. M. Biologia molecular aplicada às dermatoses tropicais. Anais Brasileiro de Dermatologia, Rio de Janeiro, v. 83, n. 3, p. 187-203, 2008.

ROURA, X.; SANCHEZ, A.; FERRER, L. Diagnosis of canine leishmaniasis by polymerase chain reaction technique. Veterinary Record, London, v. 144, n. 10, p. 262-264, 1999.

SANTOS, G. G.; MARCUCCI, G.; GUIMARÃES JÚNIOR, J.; MARGARIDO, L. C.; LOPES, L. H. C. Pesquisa de Mycobacterium leprae em biópsias de mucosa ora por meio da reação em cadeia da polimerase. Anais Brasileiro de Dermatologia, Rio de Janeiro, v. 82, n. 3, p. 245-249, 2007.

SEIXAS, G.; SALES, J. A.; OLIVEIRA, C. D.; MARUYAMA, S.; TABOADA, P. Granuloma Lepróide Canino: primeiras descrições no Centro-Oeste brasileiro. In: CONGRESSO PAULISTA DE CLÍNICOS VETERINÁRIOS DE PEQUENOS ANIMAIS, 8., 2008, São Paulo. Anais... São Paulo: Associação Nacional de Clínicos Veterinários de Pequenos Animais, 2008. p. 7475. 
SIMONATO, L. E.; GARCIA, J. F.; NUNES, C. M.; MIYAHARA, G. I. Avaliação de dois métodos de extração de DNA de material parafinado para amplificação em PCR. Jornal Brasileiro de Patologia e Medicina Laboratorial, Rio de Janeiro, v. 43, n. 2, p. 121-127, 2007.

SMITS, B.; WILLIS, R.; MALIK, R.; STUDDERT, V.; COLLINS, D. M.; KAWAKAMI, P.; GRAHAM, D.; FYFE, J. A. Case clusters of leproid granulomas in foxhounds in New Zealand and Australia. Veterinary Dermatology, Oxford, v. 23, n. 6, p. 465-e88, 2012.
THOMPSON, J. D.; GIBSON, T. J.; PLEWNIAK, F.; JEANMOUGIN, F.; HIGGINS, D. G. The CLUSTAL $\mathrm{X}$ Windows interface: flexible strategies for multiple sequence alignment aided by quality analysis tools. Nucleic Acids Research, Oxford, v. 25, n. 24, p. 48764882, 1997.

TORRES, H. M. O.; MACEDO, C. L.; MICHALANY, N. S.; LARSSON JÚNIOR, C. E.; ZANUTTO, M. S.; LARSSON, C. E. Granuloma Lepróide Canino - primo relato de caso no Nordeste brasileiro. In: CONGRESSO ESTADUAL DE MEDICINA VETERINÁRIA, 17., 2006, Gramado. Anais... Gramado: Associação Nacional de Clínicos Veterinários de Pequenos Animais, 2006. p. 12 
